\title{
MAN AND THE SOIL
}

\begin{abstract}
SYMPOSIUM, arranged jointly by the London Branches of the Institute of Biology, the Royal Institute of Chemistry, and the Institute of Physics and the Physical Society, was held on March 15 at the Senate House, University of London. The general title was "The Soil : Problems raised by its Use and Misuse", and the seven main speakers dealt with this question from the different points of view of biologists, chemists and physicists. Often a meeting of this kind, no matter how carefully planned, becomes in effect a series of unrelated papers. On this occasion the different contributions were clearly interrelated, and each contributed much to the understanding of the others.

The first speaker was Sir John Russell, who spoke on "Soil as Nature left it-Man's Use and Misuse". Sir John has, in an active working life as a soil scientist of more than sixty years, contributed more to our knowledge of the soil than any other person. He has always taken a broad view of the subject, and although he started as a chemist much of his work has elucidated problems of soil biology. On this occasion his paper did much to draw together the themes of the subsequent speakers. He showed how the equilibrium of a natural soil is upset by cultivation, and how a new equilibrium may be reached. Man may destroy the soil, but he may also prevent this destruction. Perhaps the most serious problem facing mankind to-day is whether research will be continued and applied in under-developed countries, now self-governing, so that the fertility of their soils can be maintained.
\end{abstract}

Mr. E. Crompton next spoke on "Soil Formation". $\mathrm{He}$ described the five soil-forming factors-parent material, climate, organisms, relief and time-and described how they combine to condition certain physical, chemical and biological processes occurring in the soil itself. The processes, which are the immediate mechanisms producing profile differentiation, he summarized as erosion/deposition, weathering, translocation and the organic cycle. These processes may produce many combinations, reflecting the geographical variety of the soil-forming factors.

"Physical Properties of Soil" was the title of the paper by Dr. H. L. Penman. He showed that soil physics has three aspects, for the emphasis of a technical problem may fall on the soil as a particulate system, as a porous system, or as a quasi-homogeneous system. Particle problems arise in weathering of soil, in elay mineralogy, in studies of soil structure. Pore-space problems are very important, for the biotic part of the soil needs living space, with water laid on, and some degree of air conditioning. In thermal studies, soil may be treated as homogeneous. However, ultimate explenations must go back to a study of particle properties, pore properties or both together.

Dr. G. W. Cooke spoke on "Some Chemical Aspects of Soil Fertility and Crop Production". He defined 'soil fertility' as the capacity of a soil to produce the crop desired. Fertility is not absolute, for a soil fertile enough to support a good forest may be so poor that farm crops fail on it. The term 'fertility' integrates physical and chemical factors that influenco supplies of water, air and nutrients to roots; in addition, a fertile soil must anchor plants satisfactorily and be easy to cultivate and penetrate by roots. Chemical aspects of fertility are concerned mainly with nutrient supplies and reserves, but they also involve physical factors that affect root growth and penetration. The essential nutrients obtained from soil are calcium, potassium, magnesium, nitrogen, phosphorus and sulphur (the major nutrients) required in quantities of pounds or hundredweights per acre, and the much smaller quantities of micro-nutrients (from a few grams to a few ounces per acre are needed) boron, chlorine, cobalt, copper, iron, manganese, molybdenum and zinc. The rational use of different chemical fertilizers was indicated, and the importance of available or nonavailable reserves was discussed. Chemical analysis of soils, and the relation of the results to agriculture, is still a subject requiring much research.

The first primarily biological paper was on "The Interaction of Agricultural Practice and the Soil Fauna", by Dr. K. Mellanby. He stressed our ignorance of the soil fauna, and the difficulties in studying it. No complete census of the soil fauna of any field exists. Where soil animals are pests and destroy crops, these forms have been more thoroughly studied, and successful control measures devised, but the effects of these control measures on the rest of the fauna are unknown. Soil animals are believed to affect soil structure, the breakdown of organic matter and its incorporation in the soil, but few accurate quantitative data exist. Even earthworms, which often form more than 50 per cent of the total weight of the soil fauna, are animals the biology of which we still do not understand.

Dr. S. D. Garrett spoke on "Frarming Patterns and Soil-borne Diseases of Crops". Crop rotation has, for centuries, been the main method of controlling soil-borne disease, as well as of controlling many insect pests and weeds. The efficacy of crop rotation depends on the host specialization of most parasites. Unfortunately many soil-borne diseases are caused by fungi with long-lived resting bodies, and so complete control requires rotations of undue length. 'Decoy crops' and other methods may eliminate some of the resting spores. Crop rotation alone cannot often eliminate a pest, but may keep parasite populations down to an acceptable level. Modifications of crop husbandry can prevent parasites from causing serious crop losses.

The last paper, by Mr. G. V. Jacks, was on "Climate and Erosion". He showed that four main factors determine the amount of man-accelerated soil erosion. These are land utilization, relief, erodibility of the soil, and the intensity of rain or force of wind. Land utilization is the only one of these factors controlled by man; it is also the most important, for natural erosion is generally important only in regions so arid that few crops could be grown. The importance of devising means of maintaining a complete plant cover in seasons when rain or wind would be likely to cause erosion was stressed. When this is done, the danger of erosion can be greatly decreased, and fertility restored in land already seriously affected by erosion.

KEnNETH MELLanBY 